\title{
The Medieval Warm Period redux: Where and when was it
} warm?

\author{
Lisbon, Portugal, 22-24 September 2010
}

\author{
Henry F. Diaz ${ }^{1}$, R. Trigo ${ }^{2}$, D. Barriopedro ${ }^{2}$, E. Xoplaki ${ }^{3}$, M. Hughes ${ }^{4}$ and M.E. Mann ${ }^{5}$ \\ ${ }^{1}$ Climate Diagnostics Center, NOAA/ESRL, Boulder, USA; Henry.F.Diaz@noaa.gov \\ ${ }^{2}$ Instituto Dom Luiz (IDL), University of Lisbon, Portugal; ${ }^{3}$ nnstitute of Geography, University of Bern, Switzerland; ${ }^{4}$ School of Natural Resources \\ and the Environment, University of Arizona, Tucson, USA; ${ }^{5}$ Department of Meteorology, Pennsylvania State University, University Park, USA
}

In recent years, an increasing number of studies have been published describing elements of the Medieval Climate Anomaly (MCA). The general time frame for this epoch is generally taken to span from ca. 950-1300 AD. In order to assess the most updated and comprehensive characterization of the MCA period at regional and global scales, a symposium was organized and held in Lisbon, in September 2010. The symposium topics, within the framework of the PAGES 2k Network, are at the interface of Regional Climate Dynamics and Global Earth-System Dynamics (PAGES Foci 2 and 3), and overlap with the goals of Cross-Cutting Theme 2 (Proxy development, calibration, validation) and Cross-Cutting Theme 3 (Modeling).

The main objective of the 3-day symposium was to revisit the MCA by incorporating widespread and continuous paleoclimatic evidence in a homogeneous and consistent manner, and to scale it against the instrumental temperature record to allow a meaningful quantitative comparison in the magnitude of warming against the $20^{\text {th }}$-century pace. The déjà-vu title was chosen on purpose, as the organizers wanted to revisit the question posed already in 1994 by Hughes and Diaz in their Climatic Change review "Was there a Medieval Warm Period, and if so, where and when?", taking into account that the latest IPCC report in 2007 (WG1) emphasizes the same ambivalence: "Regionally restricted evidence by itself, ... is of little practical relevance to the question of whether climate in medieval times was globally as warm or warmer than today".

The symposium, attended by 35 participants from 10 different countries including a mix of senior scientists and early career researchers, was divided in two parts: 1) Establishing the MCA Epoch as a Distinct Period, and 2) Climate Reconstruction Tools and Numerical Modeling of the MCA Climate. The first part focused on already existing and new proxies capable of resolving temperature changes in the last two millennia and covering a wide spectrum of regions (R. Bradley), including Tropical Pacific (K. Cobb), the Mediterranean basin (E. Xoplaki), western Europe

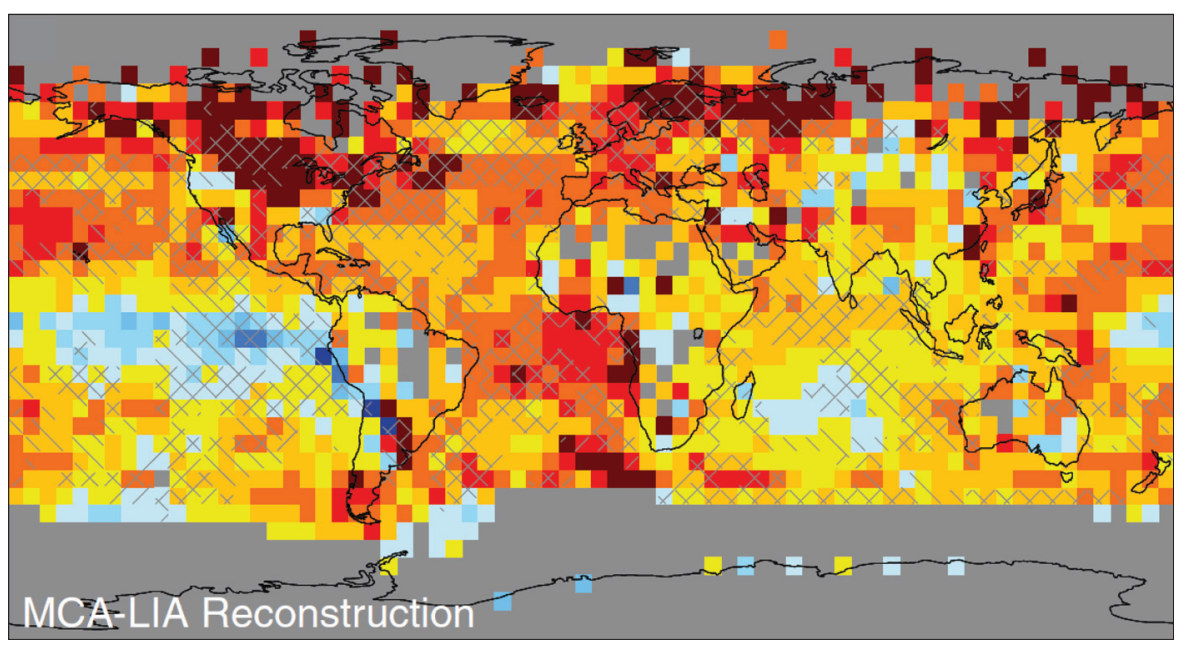

Figure 1: Reconstructed surface temperature difference (Medieval Climate Anomaly (MCA) minus Little Ice Age (LIA). Original figure from Mann et al. (2009), reprinted with permission from AAAS.

(J. Guiot; D. McCarroll; A. Moreno), North America (J. Overpeck; A. Viau), the North Atlantic (G. Miller), Greenland (B. Vinther), the Arctic (D. Fisher; D. Kaufman) and South America (J. Luterbacher). Other authors provided a wider picture on the spatial and temporal extension of the MCA event (D. Fleitmann; M. Hughes; P. Jones; F. Lungqvist; M. Mann) or the underlying large-scale dynamics associated with the MCA and the LIA period (R. D'Arrigo; V. Trouet; E. Wahl; H. Wanner). The second part of the symposium was mostly devoted to the latest results obtained by the modeling community (D. Shindell; N. Graham; F. González-Rouco), emphasizing the need for better assimilation procedures (H. Goosse), capacity to reproduce major drought and wet periods (R. Seager) but also reproduction of large-scale patterns such as the AMO (R. Oglesby) and blocking (D. Barriopedro), as well as the need to improve the characterization of the solar activity variability ( $R$. Trigo).

In summary, in answer to the question posed above regarding the spatial and temporal scales of the MCA, the general consensus of the participants is that in the past 15 years additional evidence has become available of a climatic anomaly occurring during the time interval ca. 900-1300 AD, albeit with important differences regarding the timing and spatial extent. The participants also stressed that a Northern Hemisphere or global mean value is of less relevance when looking at the regional spatial scales where the impacts of climatic anomalies are experienced.

A more detailed description including scientific conclusions of the symposium can be found in this issue of the PAGES Newsletter. A special issue in the journal Global and Planetary Change (Elsevier) has also been negotiated and the organizers are confident that a significant number of talks presented at the symposium will be published in this dedicated issue. Additionally, a review article with the current state-of-the-art consensus on the MCA epoch is currently submitted to Bulletin of American Meteorological Society.

\section{Acknowledgments}

The workshop was sponsored by PAGES, the National Oceanic and Atmospheric Administration (NOAA), the Portuguese Science Foundation (FCT) and the Luso-American Foundation (FLAD).

\section{Reference}

Mann, M.E., Zhang, Z., Rutherford, S., Bradley, R.S., Hughes, M.K., Shindell, D., Ammann, C., Faluvegi, G. and Ni, F., 2009: Global Signatures and Dynamical Origins of the Little Ice Age and Medieval Climate Anomaly, Science, 326, 1256-1260. 